\title{
DOMÍNIO COGNITIVO DA TAXONOMIA DE BLOOM APLICADO AO PROCESSO DE AVALIAÇÃO DA APRENDIZAGEM NA DISCIPLINA DE FARMACOLOGIA
}

\author{
Marcos Rogerio Sgrignoli
}

Docente do Curso Superior de Tecnologia em Estética e Cosmética - Universidade do Oeste Paulista. Email: $\underline{\text { marcosrogerio@unoeste.br }}$

\begin{abstract}
RESUMO
A taxonomia de Bloom consiste em três domínios: afetivo, psicomotor e cognitivo sendo este último o mais estudado e utilizado. A Taxonomia de Bloom visa facilitar a interação dos conhecimentos de ensinar e avaliar o aprendizado entre os professores. O objetivo deste trabalho consistiu em adequar as questões do processo de avaliação da disciplina de farmacologia com base no método de taxonomia de Bloom no domínio cognitivo e aplicá-las no ensino superior da Universidade do Oeste Paulista no Curso Superior de tecnologia em Estética e Cosmética para avaliar o processo de aprendizagem destes alunos. Os resultados dos acertos dos diferentes níveis do domínio cognitivo da taxonomia de Bloom foram: lembrar $88,23 \%$, entender $82,53 \%$, aplicar $47,5 \%$, analisar $35,29 \%$, avaliar $29,41 \%$ e criar $11,76 \%$. Esta pesquisa deixou claro que a adequação das questões auxilia no diagnóstico de erros e acertos nas metodologias de ensino do processo de avaliação da aprendizagem.
\end{abstract}

Palavras-chave: Avaliação, Taxonomia de Bloom, farmacologia, ensino-aprendizagem.

\section{INTRODUÇÃO E OBJETIVO}

A globalização da informação está acontecendo de forma rápida causando mudanças no comportamento, na atitude e no processo de educação.

Para que as técnicas pedagógicas não fiquem alheias a estas mudanças, há necessidade de se criar metodologias ativas centradas no aluno. Com isso, o professor sai de um papel de transmissor de conhecimento, para um processo de mediador do processo de aprendizagem para formar alunos com autonomia e capacidade de solucionar problemas (RON, 2010; TAVARES E CARVALHO, 2010; GALVÃO E JÓFILI, 2006).

Hoje há vários estudos em relação à avaliação da aprendizagem, que mostram as diferentes formas de avaliação (DEPRESBITERIS E TAVARES, 2009; CARVALHO E CARVALHO, 2002; PACHECO, 1998)

Campos, Herrmann e Elisabetsky, (2012) falam na dificuldade de ensinar e avaliar a disciplina de farmacologia, disciplina esta de fundamental importância para todos os cursos da área da saúde.

Neste contexto surge a taxonomia de Bloom que teve como objetivo inicial proporcionar a troca de questões entre professores de uma mesma disciplina de universidades 
diferentes que avaliavam o mesmo conhecimento transmitido (JESUS E RAABE, 2009). Portanto, a taxonomia de Bloom facilita a interação e a comunicação de idéias, técnicas e instrumentos pedagógicos e avaliativos da aprendizagem entre educadores (DÉJARDIN, 2012; NETO, SANTOS E ASSIS, 2012; PILLA JR E FERLIN, 2011; FERRAZ E BELHOT 2010; TAVARES E CARVALHO, 2010; JESUS E RAABE, 2009; DUGARTE, 2002).

$\mathrm{Na}$ esfera da educação, esta taxonomia foi utilizado por Benjamin S. Bloom e seus colaboradores na busca de uma forma de facilitar a interação do conhecimento de ensinar e avaliar o aprendizado entre professores de várias universidades (DÉJARDIM, 2012; JESUS E RAABE, 2009).

A taxonomia original de Bloom consiste de três domínios (DÉJARDIN, 2012; NETO, SANTOS e ASSIS, 2012; FERRAZ E BELHOT, 2010; BITTENCOURT E GIRAFFA, 2003): cognitivo que diz respeito à capacidade do aluno em assimilar e memorizar um conteúdo, método, critério, teoria, podendo assim dominá-lo, para desenvolver atividades utilizando os conhecimentos adquiridos (NETO, SANTOS e ASSIS, 2012; FERRAZ, BELHOT, 2010); afetivo que segundo FERRAZ e BELHOT (2010), as categorias deste domínio são: receptividade, respostas, valorização e organização. Essas categorias estão ligadas a áreas sentimentais, posturais, emocionais e afetivas, que levam a comportamentos, atitudes, responsabilidades e valores; e psicomotor onde Bloom e seus colaboradores em 1956, ano em que começou o desenvolvimento da hoje conhecida como taxonomia de Bloom, não chegaram a definir características desse domínio. Mas outros pesquisadores chegaram a seis categorias: reflexos, percepção, habilidades físicas, movimentos aperfeiçoados e comunicação não verbal (FERRAZ E BELHOT, 2010).

Entre os três domínios da taxonomia de Bloom, o mais estudado e utilizado atualmente é o domínio cognitivo (FERRAZ E BELHOT, 2010).

As categorias originais da taxonomia de Bloom segundo Déjardin, (2012); Jesus e Raabe, (2009); Rodrigues, (1994); Bloom et al., (1972), são: conhecimento: capacidade do aluno em relembrar com precisão de uma informação absorvida seja ela uma fórmula, uma teoria, um método; compreensão: o aluno deve alcançar um nível de entendimento do conteúdo absorvido onde ele possa agregar, resumir, representar a informação original; aplicação: Nessa categoria, o aluno deve conseguir aplicar a teoria à prática; análise: 0 aluno terá que fragmentar o conhecimento adquirido, estabelecendo a relação entre eles; síntese: o aluno deve ser capaz de resumir vários conhecimentos, unindo-os para criar algo novo; e avaliação: consiste na capacidade de diagnosticar o que já foi aprendido e o que ainda deverá ser assimilado de um conhecimento. 
Segundo Déjardin, (2012); Krathwohl, (2002), Bloom e seus colaboradores, para chegar a um nível de compreensão (agregar, resumir, representar), deve-se primeiro lembrar do conhecimento adquirido anteriormente. Da mesma forma, para o aluno chegar a um nível de aplicação do aprendizado, ele deve ter conhecimento (capacidade de lembrar com detalhes do aprendizado) e compreensão da teoria e assim sucessivamente, ou seja, as categorias dos níveis cognitivos (conhecimento, compreensão, aplicação, análise, síntese e avaliação) estão expostas do nível mais simples (conhecimento) para o mais complexo (avaliação). Portanto, para se chegar a um nível acima, o aluno deve dominar os níveis inferiores da categoria dos níveis cognitivos.

Fuller et al., (2007), em seu trabalho, diz que as categorias do domínio cognitivo não são fáceis de serem aplicadas, por isso, existem debates sobre a ordem em que as categorias análise, síntese e avaliação aparecem hierarquicamente. Diante disso modificações foram feitas pelas revisões, onde as palavras que eram substantivos, passaram a ser verbos alterando também as suas posições hierárquicas, ficando assim: os níveis conhecimento, compreensão, aplicação, análise passaram a ser respectivamente, lembrar, entender, aplicar e analisar. O nível síntese passou a ser criar e este nível tornou-se o último nível do domínio cognitivo. O nível avaliação tornou-se avaliar e deixou de ser o último nível do domínio cognitivo (KRATHWOHL, 2002).

Segundo Jesus e Raabe, (2009), em cada nível já mencionado do domínio cognitivo da taxonomia de Bloom, existem verbos que auxiliam na elaboração de uma questão de avaliação. Os verbos mais utilizados nos níveis lembrar, entender, aplicar, analisar, avaliar e criar são: relembrar, exemplificar, executar, diferenciar, criticar e elaborar respectivamente.

O objetivo deste trabalho foi adequar as questões do processo de avaliação da disciplina de farmacologia com base no método de taxonomia de Bloom e aplicá-las no ensino superior da Universidade do Oeste Paulista no Curso Superior de tecnologia em Estética e Cosmética para avaliar o processo de aprendizagem destes alunos.

\section{METODOLOGIA}

Seis questões dissertativas, sendo uma de cada nível (Domínio cognitivo da taxonomia de Bloom modificada) foram elaboradas e aplicadas no primeiro semestre do ano de dois mil e treze, a uma turma de dezessete alunos do quarto termo do Curso Superior de Tecnologia em Estética e Cosmética da Universidade do Oeste Paulista. Os resultados foram coletados para posterior avaliação do ensino e aprendizagem. 
As questões elaboradas e aplicadas foram: no nível "lembrar" a pergunta foi: Relembre as características das substâncias específicas e descreva as principais delas. No nível "entender" a pergunta foi: Relembre as características das substâncias específicas descrevendo e exemplificando as principais delas. No nível "aplicar" a pergunta foi: Um cliente está a seis meses realizando um tratamento estético obtendo bons resultados, mas no último mês esse tratamento não vem surtindo tanto efeito. Conversando com o cliente, você descobre que no último mês, ele vem fazendo uso de um medicamento injetável. Pesquisando, você descobre que tanto o creme estético quanto o medicamento são substâncias agonistas. Que procedimento você executaria neste cliente para que o tratamento volte a ter resultados?. No nível "analisar" a pergunta foi: Um cliente está a seis meses realizando um tratamento estético obtendo bons resultados, mas no último mês esse tratamento não vem surtindo tanto efeito. Conversando com o cliente, você descobre que no último mês, ele vem fazendo uso de um medicamento injetável. Pesquisando, você descobre que tanto o creme estético quanto o medicamento são substâncias agonistas. Analise o caso clínico, explique porque o tratamento não está mais tendo resultados satisfatórios e sugira uma possível solução para que o tratamento volte a ter resultados. No nível "avaliar" a pergunta foi: Um cliente está a seis meses realizando um tratamento estético em uma clínica, obtendo bons resultados, mas no último mês esse tratamento não vem surtindo tanto efeito. Ele vai até a sua clínica de estética para que você tente solucionar o problema. Conversando com o cliente, você descobre que no último mês, ele vem fazendo uso de um medicamento injetável. O esteticista que estava realizando o tratamento sugeriu a associação de outro creme de tratamento que antagonizasse o efeito da injeção, mas o cliente não concordou e disse que iria pedir a opinião de outro esteticista. Pesquisando, você descobre que tanto o creme estético quanto o medicamento são substâncias agonistas. Avalie o caso clínico, dizendo se o protocolo de tratamento sugerido pelo primeiro esteticista é o mais adequado. Caso não seja, sugira outro protocolo de tratamento explicando qual a vantagem. No nível "criar" a pergunta foi: Elabore um protocolo de tratamento para estrias e celulites em um cliente que utiliza creme antienvelhecimento em todo corpo diariamente.

\section{RESULTADOS}

Os resultados obtidos foram: $88,23 \%$ (15 alunos) de acerto na questão do nível "lembrar", do domínio cognitivo da taxonomia de Bloom. Já no nível "entender" o índice de acerto foi um pouco menor ficando na casa de $82,53 \%$ (14 alunos) de acerto. O nível "aplicar" teve uma 
acentuada diminuição no número de acerto em relação ao nível anterior, onde somente 47,05\% (8 alunos) dos alunos conseguiram responder a questão, 35,29\% (6 alunos) dos alunos responderam a pergunta do nível "analisar", 29,41\% (5 alunos) responderam a pergunta do nível "avaliar" e somente $11,76 \%$ ( 2 alunos) dos alunos conseguiram solucionar a questão do nível "criar".

\section{DISCUSSÃO}

A questão do nível "lembrar" é de baixa complexidade exigindo que o aluno relembre (JESUS E RAABE, 2009, THOMPSON, et. al, 2008) as características das substâncias específicas que são: interagir com alta afinidade ao receptor causando uma atividade intrínseca celular de agonismo ou antagonismo, dependendo do tipo de substância.

O nível de acerto desta questão foi alto, ficando na casa de $88,23 \%$. Este número de acerto é explicado pelo baixo índice de complexidade da pergunta, onde o aluno só tem que se lembrar das características citadas em aula.

Para responder a questão do nível "entender", o aluno tem que primeiro relembrar as características das substâncias específicas para depois exemplificar e explicá-las. Para isso é necessário que o aluno esteja no segundo nível do domínio cognitivo da taxonomia de Bloom, pois terá que lembrar e entender sobre o assunto (DÉJARDIN, 2012).

Neste nível, devido ao índice um pouco mais complexo na elaboração da pergunta, houve um número um pouco menor de acerto em relação ao nível anterior, tendo $82,35 \%$ de acerto.

No nível "aplicar", para que o aluno responda a esta questão, é necessário que ele se lembre das características de uma substância específica e entenda (JESUS E RAABE, 2009) o seu mecanismo de ação para que ele possa identificar o problema e sugerir uma solução na prática que possa resolver o caso clínico. Portanto, o aluno deve lembrar que substâncias específicas atuam em receptores e são agonistas ou antagonistas e que duas substâncias agonistas podem causar antagonismo fisiológico. E para solucionar o problema pode-se interromper o uso do medicamento injetável evitando assim o antagonismo fisiológico, ou substituir o creme por outro que não atue contrariamente às substâncias injetáveis.

A queda no número de acerto no nível "aplicar" foi mais acentuada do que nas anteriores ficando na casa de $47,05 \%$. Isto mostra que este nível exige do aluno não só a capacidade de lembrar, compreender mais também de aplicar este conhecimento na prática (JESUS E RAABE, 2009) do seu dia a dia de trabalho. Nos níveis anteriores, a complexidade não era 
tão grande, tendo assim um número de acerto grande. Para aplicar o conhecimento na prática o aluno dever ter os níveis anteriores muito bem compreendido, diferente de para responder as questões nos níveis anteriores, ou seja, para responder a questões no nível "entender" o nível de compreensão é menor que para responder a pergunta no nível "aplicar".

Para responder a questão do nível "analisar" o aluno além de ter um nível de conhecimento amplo dos níveis anteriores deve ter a capacidade de analisar o caso clínico para diagnosticar o problema e sugerir uma solução (KRATHWOHL, 2002).

A diferença do nível de compreensão para responder questões do nível "aplicar" em relação ao nível "analisar" é muito sutil e isto é comprovado pela pequena queda no número de acertos de um nível para o outro sendo respectivamente de $47,05 \%$ para $35,29 \%$.

A pergunta do nível "avaliar" exige que o aluno saiba bem as características de uma substância específica e entenda o seu mecanismo de ação para poder avaliar o protocolo de tratamento e saber se é o mais indicado (JESUS E RAABE, 2009), e caso não seja, poder sugerir um protocolo adequado.

No nível "avaliar" ocorreu o mesmo que no anterior (analisar), uma pequena diferença no nível de compreensão exigindo somente que o aluno tenha a mais, a capacidade crítica, por isto a pequena queda de $35,29 \%$ para $29,41 \%$ no número de acertos.

Apesar de ser de simples interpretação, a questão do nível "criar" exige um estágio de compreensão muito elevado dos níveis cognitivos anteriores (JESUS E RAABE, 2009) para ter domínio de todos os parâmetros necessário para montar um protocolo de tratamento, visto que o cliente faz uso de um creme que interfere no tratamento.

Os resultados nos mostram com clareza que quanto maior o nível de compreensão em relação a um determinado assunto em uma pergunta, maior a dificuldade dos alunos responderem a esta questão (KRATHWOHL, 2002). Um dos fatores que podem explicar esse fato pode ser a metodologia aplicada no ensino, ficando claro que devido a complexidade do tema e a aula desmotivadora faz com que os alunos tenham um baixo índice de aproveitamento apresentando dificuldade no aprendizado (MORAN et al., 2000) dos últimos níveis do domínio cognitivo da taxonomia de Bloom.

Uma possível solução para aumentar o índice de motivação e assim alavancar o aproveitamento das aulas seria a utilização de novas tecnologias como vídeo aulas que mostram os mecanismos de ação de cada tipo de substância, pois, o estímulo somente auditivo das aulas teóricas é facilmente superado quando associados ao estímulo visual (MORAN et al., 2000). 


\section{CONCLUSÃO}

Esta pesquisa deixou claro que a adequação das questões auxilia no diagnóstico de erros e acertos nas metodologias de ensino do processo de avaliação da aprendizagem. Diante disso, há uma necessidade de adequar as metodologias de ensino para melhorar o índice de compreensão dos alunos em relação aos níveis mais avançados do domínio cognitivo da taxonomia de Bloom.

\section{REFERÊNCIAS}

BITTENCOURT, J. R.; GIRAFFA, L. M. M. Modelando ambientes de aprendizagem virtuais utilizando Role-Playing Games. In: Simpósio Brasileiro de Informática na Educação, 14, Rio de Janeiro. Anais eletrônicos... Rio de Janeiro, 2003. Disponível em: http://www3.pucrs.br/pucrs/files/uni/poa/facin/pos/relatoriostec/tr031.pdf Acesso em: 28 março 2013.

BLOOM, B. S.; ENGELHART, M.D.; FURST, E.J.; HILL, W.H.; KRATHWOHL, D.R. Taxionomia de objetivos educacionais. 1a Ed., - 1 - Domínio cognitivo. Editora Porto Alegre: globo, 1972.

CAMPOS, L. C.; HERRMANN, A. P.; ELISABETSKY, E. O método "Avaliação pelos pares" na disciplina de Farmacologia biomédica I do curso de Biomedicina da UFRGS. Out. 2012.

CARVALHO, M. G. H.; CARVALHO, M. A. Avaliação da aprendizagem: uma evolução histórica. 2002.

DÉJARDIN, I. P. Limites e possibilidades educacionais da taxonomia de Bloom no contexto dos jogos RPG digitais. in: VI Colóquio Internacional "Educação e Contemporaneidade" - São Cristovão - S.E, 2012.

DESPRESBITERIS, L. TAVARES, M. R. Diversificar é preciso: instrumentos e técnicas de avaliação da aprendizagem. São Paulo: Editora Senac São Paulo, 2009.

DUGARTE, A. M. Taxonomia educativa integradora como estratégia didática para la planificación instruccional. Rev. Ciencias de la Educacion, Ano 2, n. 20. 2002.

FERRAZ, A. P. C. M.; BELHOT, R. V. Taxonomia de Bloom: revisão teórica e apresentação das adequações do instrumento para definição de objetivos instrucionais. Gest Prod., São Carlos, v. 17, n. 2, p. 412-431, 2010.

FULLER, U.; JOHNSON C. G.; AHONIEMI, T.; CUKIERMAN, D.; LOSADA, I. H.; JACKOVA, J.; LAHTINEN, E.; LEWIS, T. L.; THOMPSON, D. M.; RIEDESEL. C.; THOMPSON, E. Developing a Computer ScienceSpecific Learning Taxonomy. In: SIGCSE, USA, v.39, n. 4, p. 152-170. 2007.

GALVÃO, M. A. R.; JÓFILI, Z. M. S. O lugar dos objetivos no ensino de matemática. In: Simpósio Internacional de Pesquisa em Educação Matemática. 2006. 
JESUS, E. A.; RAABE, A. L. A. Interpretações da taxonomia de Bloom no contexto da programação introdutória. In: XX Simpósio Brasileiro de Informática na Educação. 2009.

KRATHWOHL, D. R. A revision of bloom`s taxomomy: an overview. In: Theory into Practice. v. 4, n. 41, p. 212-218. 2002. http://dx.doi.org/10.1207/s15430421tip4104 2

MORAN, J. M.; MASETTO, M. T.; BEHRENS, M. A. Novas tecnologias e mediação pedagógica. Campinas: Papirus, 2000.

NETO, R. J.; SANTOS, N.; ASSIS, B. C. Análise das habilidades cognitivas fundamentados na taxonomia de Bloom: uma análise no curso de Ciências Contábeis. 2012.

PACHECO. J. A. A avaliação da aprendizagem. 1998.

PILLA JR, V.; FERLIN, E. P. Os níveis de aprendizagem da taxonomia de Bloom aplicados em uma disciplina de um curso de Engenharia da Computação. 2011

RODRIGUES, J. A taxonomia de objetivos educacionais - um manual para o usuário. 2 Ed., Brasília: Editora UNB, 1994.

RON. R. R. D. Planejamento de ensino e avaliação da aprendizagem para cursos estruturados com base em competências. Rev. Elet. de Educ. e Tec. Do SENAI-SP. ISSN: 1981-8270. v. 4, n. 8, mar. 2010.

TAVARES, R.; CARVALHO, C. O mapa conceitual hierárquico e a taxonomia de Bloom modificada. In: VI encontro Interncaional e 3a encontro nacional de Aprendizagem Significativa. Jul. 2010.

THOMPSON, E. et. al. "Bloom's taxonomy for CS assessment", in: X Australasian Computing Education Conference (ACE2006), Computer Society, p. 243-252, 2008. 